\title{
BIOANALYTICAL METHOD DEVELOPMENT AND VALIDATION OF CANAGLIFLOZIN IN HUMAN PLASMA BY LIQUID CHROMATOGRAPHY-TANDEM MASS SPECTROMETRY
}

\author{
DEEPAN T ${ }^{1,2}$, BASAVESWARA RAO MV ${ }^{1}$, DHANARAJU MD ${ }^{2 *}$ \\ ${ }^{1}$ Department of Pharmacy, Krishna University, Machilipatnam, Andhra Pradesh, India. ${ }^{2}$ Department of Pharmaceutics, GIET School of \\ Pharmacy, Rajahmundry, Andhra Pradesh, India. Email: mddhanaraju@yahoo.com
}

Received: 12 April 2019, Revised and Accepted: 10 June 2019

\section{ABSTRACT}

Objective: A validated liquid chromatography-tandem mass spectrometry (LC-MS/MS) method was developed for canagliflozin in human plasma along with stability studies.

Methods: The chromatographic separation of canagliflozin was performed on Zorbax XDB phenyl (75 $\times 4.6 \mathrm{~mm}, 3.5 \mathrm{~mm})$ using methanol:acetate buffer $(80: 20 \mathrm{v} / \mathrm{v})$ at a flow rate of $1.0 \mathrm{ml} / \mathrm{min}$. The LC-MS/MS system consists of API 4000 triple quadrupole mass spectrometer equipped with turbospray ionization and an AS8020 automatic sample injector.

Results: The retention time of canagliflozin was $1.15 \mathrm{~min}$ and total runtime was $2 \mathrm{~min}$. The multiple reaction monitoring was $462.5 / 267.1$ (m/z) for canagliflozin and 466.4/267.2 (m/z) for internal standard (canagliflozin $\mathrm{D}_{4}$ ), respectively. The method was linear over the range of $10-7505 \mathrm{ng} / \mathrm{ml}$. The calculated slope ranged from 0.0451 to 0.0502 and intercepts from 0.0102 to 0.0456 with coefficients of the determination of 0.9970 . The overall mean recovery of internal standard and canagliflozin was 76.66 and 79.77 , respectively.

Conclusion: The method was successfully validated and it was found to be within the limits for accuracy, precision, and linearity and it is stable under analytical conditions used.

Keywords: Canagliflozin, Liquid chromatography-tandem mass spectrometry, Human plasma, Liquid-liquid extraction, Validation, Stability studies.

(C) 2019 The Authors. Published by Innovare Academic Sciences Pvt Ltd. This is an open access article under the CC BY license (http://creativecommons. org/licenses/by/4. 0/) DOI: http://dx.doi.org/10.22159/ajpcr.2019.v12i8.33228

\section{INTRODUCTION}

Canagliflozin chemically is (2S.3R, 4R, 5S, 6R)-2-(3-\{[5-(4-flurophenyl) thiophenyl) thiopen-2-yl] methyl\}-4 methyl phenyl)-6-(hydroxy methyl) oxane-3, 4, 5,-triol represented in Fig. 1 (Drug bank) [1]. The molecular formula is $\mathrm{C}_{24} \mathrm{H}_{25} \mathrm{FO}_{5} \mathrm{~S}$ and molecular weight is $444.52 \mathrm{~g} / \mathrm{mol}$. Canagliflozin is classified as SGLT-2 inhibitor, a new class of antidiabetic drug having an insulin-dependent mechanism that offers a considerable advantage of increasing urinary glucose excretion without inducing hypoglycemia [2]. Several analytical methods such as ultraviolet [3], high-performance liquid chromatography (HPLC) [4-7], high-performance thin-layer chromatography [8], liquid chromatography-tandem mass spectrometry (LC-MS/MS) [9-11] have been developed for analysis of canagliflozin. There are methods developed for canagliflozin in rat plasma. However, there is no method reported for canagliflozin in human plasma along with stability studies. This study describes that a validated LC-MS/MS method was developed for canagliflozin in human plasma along with stability studies.

\section{METHODS}

Chemicals and reagents

Canagliflozin and internal standard (canagliflozin $\mathrm{D}_{4}$ ) were obtained from Piramal Healthcare. K3EDTA plasma was from local suppliers, acetonitrile and methanol were of HPLC grade, ammonium acetate (GR grade) was used, and water was from Milli Q system.

\section{Instrumentation}

The HPLC separation was achieved on Zorbax XDB phenyl $(75 \times 4.6 \mathrm{~mm}$, $3.5 \mathrm{~mm})$ using methanol:acetate buffer $(80: 20 \mathrm{v} / \mathrm{v})$ at a flow rate of $1.0 \mathrm{ml} / \mathrm{min}$. The injection volume was $10 \mu \mathrm{l}$ and the column temperature was $30^{\circ} \mathrm{C}$. The samples were held at $5 \pm 3^{\circ} \mathrm{C}$ in an autosampler.
The runtime was $2.0 \mathrm{~min}$. The LC-MS/MS system consists of API 4000 triple quadrupole mass spectrometer equipped with turbospray ionization and an AS8020 automatic sample injector. The multiple reaction monitoring (MRM) was 462.5/267.1 (m/z) for canagliflozin and 466.4/267.2 (m/z) for internal standard (canagliflozin $\mathrm{D}_{4}$ ), respectively. The temperature of the capillary was $50^{\circ} \mathrm{C}$ and the dwell time was 100 millisecond or ms.

Preparation of standards and quality control (QC) samples Stock solution of canagliflozin was prepared in methanol to get concentration of $5 \mu \mathrm{g} / \mathrm{ml}$. The calibration curve standard solution was prepared by further diluting the stock solution in methanol to the following analytical condition $(10,25,150,375,750,1875$, 3750,6000 , and $7500 \mathrm{ng} / \mathrm{ml}$ ) for canagliflozin. The internal standard working solution was prepared by diluting stock solution in methanol to $5000 \mathrm{ng} / \mathrm{ml}$. QC samples were prepared in the same manner from the QC stock to get final concentration of 28 (LQC), 706 middle QC (MQC), and 5700 high QC (HQC) in plasma. QC samples were stored in deep freezer with study samples and include with all validation and sample analysis runs.

\section{Extraction procedure}

To a glass tube containing $300 \mu \mathrm{l}$ of plasma sample, added $50 \mu \mathrm{l}$ of $2000 \mathrm{ng} / \mathrm{ml}$ internal standard working solution. The sample was mixed on a vortex mixer for approximately $5 \mathrm{~s}$. Then, $2.0 \mu \mathrm{l}$ of tertiary butyl methyl ether was added to the vials and extracted for a period of $15 \mathrm{~min}$ or rotospin at $40 \mathrm{rpm}$. The vials were centrifuged at $4500 \mathrm{rpm}$ at $4 \pm 1^{\circ} \mathrm{C}$ for $5 \mathrm{~min}$. Finally, the samples $(1.8 \mu \mathrm{l})$ were eluted into a deep well collection plate evaporated to dryness under nitrogen at $40 \pm 5^{\circ} \mathrm{C}$ and reconstituted in $300 \mu \mathrm{l}$ of solution of mixture of acetonitrile:phosphate buffer (80:20\%) vortexed for about $10 \mathrm{~s}$, and finally, $10 \mu \mathrm{l}$ of each reconstituted sample extract was injected into LC-MS/MS. 


\section{Assay validation}

The method was validated as per Food and Drug Administration guidance for bioanalytical method validation [12].

\section{Accuracy and precision}

The accuracy and precision of the proposed method were determined using QC samples (low, medium, and high) over the concentration of $28-5750 \mathrm{ng} / \mathrm{ml}$ for assay precision and accuracy. Six QC validation levels such as DQC, LQC, MQC3, MQC2, MQC1, and HQC were tested. The accuracy and intraday precision of the assay method were performed on three different runs, each run containing duplicate full calibration curves and six samples for each of the six QC levels. The recovery from human plasma during extraction was determined at LQC, MQC1, and HQC levels for canagliflozin by comparing the response ratios in human plasma sample with those of QC sample spiked in the supernatant of the extracted blank plasma. The LLOQ was assessed using plasma samples at $10 \mathrm{ng} / \mathrm{ml}$ for canagliflozin, the lowest concentration in the standard curves. Six different lots of control human plasma were spiked to obtain the six LLOQ samples. The LLOQ samples were processed and analyzed with standard curves and QC samples.

The matrix effect was determined at low- and high-level QC for canagliflozin. The absolute matrix factors for three QC samples were determined by comparing the peak area of the QC sample spiked in the mobile phase with those in the supernatant of extracted blank plasma.

\section{Stability studies}

The stability studies of canagliflozin in human plasma were evaluated using QC samples (low, medium, and high concentration) under various conditions. The autosampler stability was evaluated by analyzing QC samples that had been stored under conditions $\left(5 \pm 3^{\circ} \mathrm{C}\right)$ and room temperature for 3 days. The long-term stability was also evaluated by analyzing QC samples that had been stored at $2-8^{\circ} \mathrm{C}$ for 7 days. Freeze-thaw stability was also evaluated by analyzing HQC and LQC samples after freezing at $-28 \pm 5^{\circ} \mathrm{C}$ and thawing at room temperature 5 times.

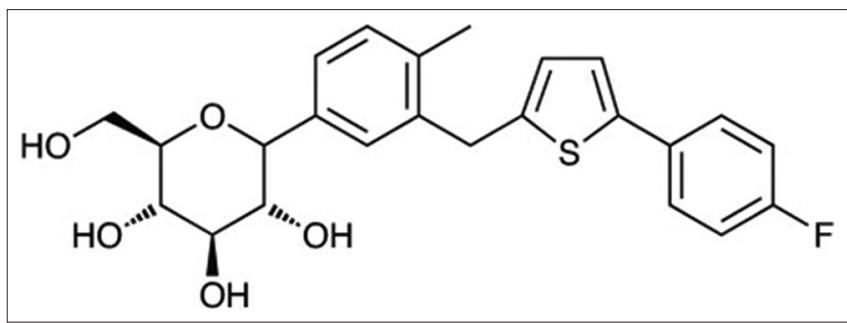

Fig. 1: Chemical structure of canagliflozin
The stability was established if the average of the six determinations was within $15 \%$ and no obvious trend was observed.

\section{RESULTS AND DISCUSSION}

In the present study, LC-MS/MS assay was developed for positive ionization which was evaluated. The full scan mass spectrum of canagliflozin and internal standard in the positive MRM is presented in Figs. 2 and 3. The reliability of the method was assessed on the basis of linearity, precision, selectivity, accuracy, recovery, and carryover test. Finally, the chromatographic separation was carried out on a combination of methanol:acetate buffer $(80: 20 \mathrm{v} / \mathrm{v})$ at a flow rate of $1.0 \mathrm{ml} / \mathrm{min}$ which resulted in a separation time of $1.15 \mathrm{~min}$ for analyte and internal standard.

\section{Accuracy and precision}

The interbatch coefficient of variation ranged from 2.86 to 5.61 and percentage accuracy ranged from 101.61 to 109.86 for canagliflozin. The results for within and between in batch precision for LQC, MQC, and HQC should be $<15.00 \%$, and for the LLOQ it should be $<20.00 \%$. The intrabatch coefficient of variation ranged from 2.80 to 4.97 and the percentage accuracy ranged from 102.04 to $110.38 \%$ for canagliflozin. The precision ranged from 2.58 to $3.39 \%$. The results prove that the canagliflozin and internal standard can remain in autosampler for $67 \mathrm{~h}$ $15 \mathrm{~min}$, without showing a significant loss indicates that the sample should be analyzed within this period. The results are shown in Table 1.

\section{Linearity}

The method was linear over the range of $10-7505 \mathrm{ng} / \mathrm{ml}$. The calculated slope ranged from 0.0451 to 0.0502 and intercepts from 0.0102 to 0.0456 with coefficients of the determination of 0.9970 or higher.

\section{Recovery}

The mean recovery of canagliflozin and canagliflozin $\mathrm{D}_{4}$ (internal standard) was evaluated by comparing peak mean peak response of LQC, MQC1, and HQC sample to those of diluted aqueous solution. The overall mean recovery of internal standard and canagliflozin was 76.66 and 79.77, respectively. The overall percentage coefficient of variation was 3.94. This indicates that the method has good recovery of both analyte and internal standard. The results are shown in Tables 2 and 3.

\section{Matrix effect}

No significant matrix effect was observed in all the eight batched for canagliflozin at LQC and HQC concentrations. The precision for internal standard normalized matrix factor at LQC and HQC level was found to be $2.46 \%$ and $3.84 \%$, respectively. The precision of internal standard normalized matrix at each level (HQC and LQC) should be $<15.00$. The above-reported method showed that no matrix effect was found for plasma and shown in Table 4.

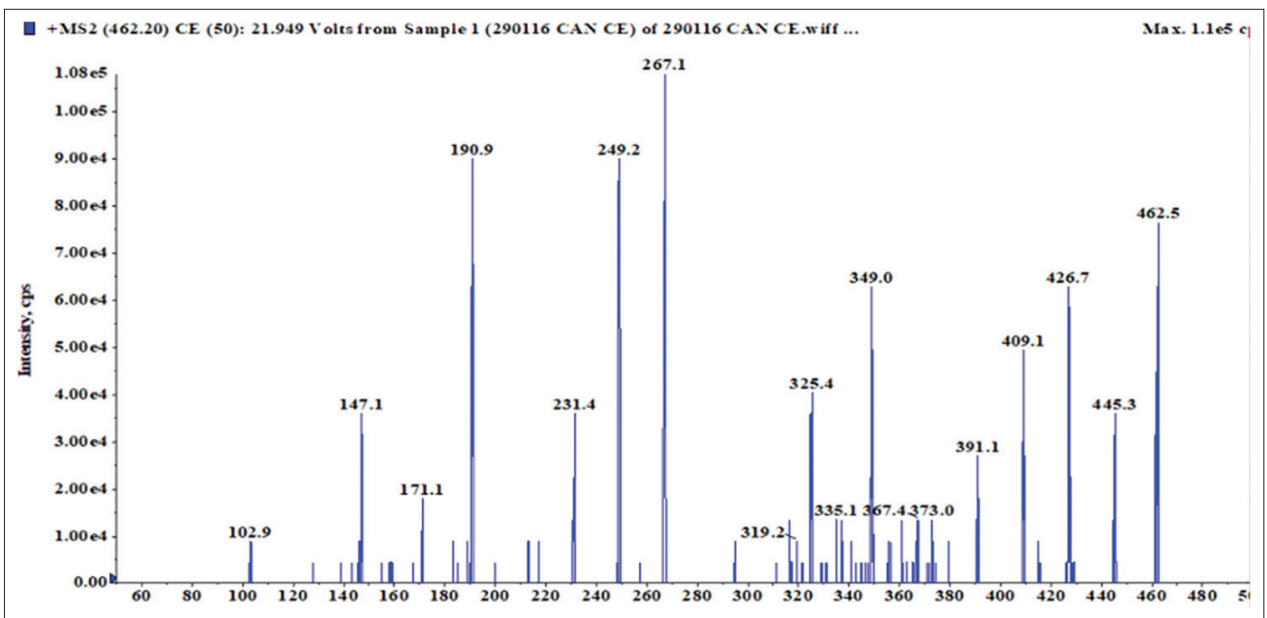

Fig. 2: Mass spectra of canagliflozin 


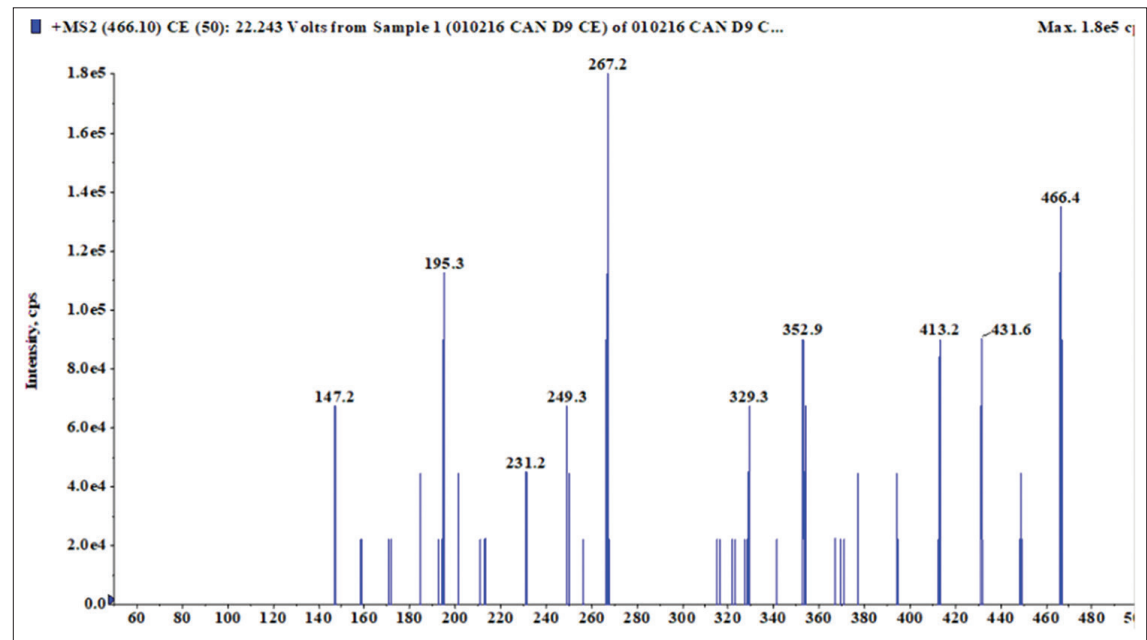

Fig. 3: Mass spectra of canagliflozin $D_{4}$

Table 1: Accuracy and precision of canagliflozin

\begin{tabular}{|c|c|c|c|c|c|c|c|c|c|}
\hline \multirow[t]{2}{*}{ S. No. } & \multirow[t]{2}{*}{ Q.C nom. conc. (ng/ml) } & \multicolumn{2}{|c|}{ Mean (ng/ml) } & \multicolumn{2}{|c|}{ Precision (CV \%) } & \multicolumn{2}{|c|}{ Accuracy (\%) } & \multicolumn{2}{|l|}{ SD } \\
\hline & & Intra & Inter & Intra & Inter & Intra & Inter & Intra & Inter \\
\hline 1. & LQC (28.89) & 29.48 & 30.25 & 4.89 & 4.15 & 102.0 & 104.73 & 1.44 & 1.25 \\
\hline 3. & HQC (5750.45) & 6007.72 & 5843.0 & 2.80 & 4.42 & 104.4 & 101.61 & 168.3 & 258.4 \\
\hline
\end{tabular}

Q.C nom. conc.: Quality control nominal concentration. CV: Coefficient of variation, SD: Standard deviation, HQC: High-quality control, MQC: Middle-quality control, LQC: Low-quality control, QC: Quality control

Table 2: Recovery for canagliflozin

\begin{tabular}{|c|c|c|c|c|c|c|}
\hline \multirow[t]{2}{*}{ S. No. } & \multicolumn{2}{|l|}{ HQC } & \multicolumn{2}{|l|}{ MQC1 } & \multicolumn{2}{|l|}{ LQC } \\
\hline & $\begin{array}{l}\text { Post-extracted } \\
\text { response }\end{array}$ & $\begin{array}{l}\text { Extracted } \\
\text { response }\end{array}$ & $\begin{array}{l}\text { Post-extracted } \\
\text { response }\end{array}$ & $\begin{array}{l}\text { Extracted } \\
\text { response }\end{array}$ & $\begin{array}{l}\text { Post-extracted } \\
\text { response }\end{array}$ & $\begin{array}{l}\text { Extracted } \\
\text { response }\end{array}$ \\
\hline 1. & $4,002,365$ & $3,023,654$ & $2,869,574$ & $2,236,577$ & 31,564 & 25,645 \\
\hline 2. & $3,485,623$ & $3,125,678$ & $2,798,654$ & $2,045,689$ & 30,214 & 24,587 \\
\hline 3. & $3,698,756$ & $3,256,891$ & $2,856,457$ & $2,145,689$ & 32,564 & 21,457 \\
\hline 4. & $3,789,562$ & $3,369,871$ & $2,903,654$ & $2,365,894$ & 33,456 & 25,487 \\
\hline 5. & $3,895,647$ & $3,045,689$ & $2,778,965$ & $2,265,436$ & 31,265 & 26,354 \\
\hline 6. & $3,957,863$ & $3,256,489$ & $2,812,654$ & $2,154,879$ & 30,125 & 25,487 \\
\hline Mean & $3,804,969.3$ & $3,179,712.0$ & $2,836,659.7$ & $2,202,360.7$ & $31,531.3$ & $24,836.2$ \\
\hline SD & $191,866.99$ & $136,563.31$ & $47,566.60$ & $111,269.59$ & 1308.12 & 1748.49 \\
\hline$\% \mathrm{CV}$ & 5.04 & 4.29 & 1.68 & 5.05 & 4.15 & 7.04 \\
\hline \multicolumn{2}{|c|}{$\%$ mean recovery } & 79.99 & & & & \\
\hline \multicolumn{2}{|c|}{ SD } & 3.149 & & & & \\
\hline \multicolumn{2}{|l|}{$\% \mathrm{CV}$} & 3.94 & & & & \\
\hline
\end{tabular}

HQC: High-quality control, MQC: Middle-quality control and LQC: Low-quality control, CV: Coefficient of variation, SD: Standard deviation

Table 3: Recovery for internal standard

\begin{tabular}{|c|c|c|c|c|c|c|}
\hline \multirow[t]{2}{*}{ S. No. } & \multicolumn{2}{|l|}{ HQC } & \multicolumn{2}{|l|}{ MQC1 } & \multicolumn{2}{|l|}{ LQC } \\
\hline & $\begin{array}{l}\text { Post-extracted } \\
\text { response }\end{array}$ & $\begin{array}{l}\text { Extracted } \\
\text { response }\end{array}$ & $\begin{array}{l}\text { Post-extracted } \\
\text { response }\end{array}$ & $\begin{array}{l}\text { Extracted } \\
\text { response }\end{array}$ & $\begin{array}{l}\text { Post-extracted } \\
\text { response }\end{array}$ & $\begin{array}{l}\text { Extracted } \\
\text { response }\end{array}$ \\
\hline 1. & 155,645 & 112,356 & 165,234 & 125,645 & 225,687 & 190,365 \\
\hline 2. & 145,687 & 110,234 & 160,324 & 120,364 & 245,897 & 185,641 \\
\hline 3. & 149,654 & 120,236 & 166,354 & 130,324 & 201,365 & 189,654 \\
\hline 4. & 150,234 & 115,234 & 160,324 & 131,256 & 223,654 & 175,654 \\
\hline 6. & 152,364 & 108,654 & 185,364 & 125,847 & 232,254 & 170,235 \\
\hline Mean & $150,803.0$ & $111,179.7$ & $166,209.0$ & $127,133.5$ & $227,567.0$ & $181,518.7$ \\
\hline SD & 3282.83 & 6694.63 & 9799.19 & 4046.00 & $15,125.82$ & 8231.62 \\
\hline$\% \mathrm{CV}$ & 2.18 & 6.02 & 5.90 & 3.18 & 6.65 & 4.53 \\
\hline \multicolumn{2}{|c|}{$\%$ mean recovery } & 76.66 & & & & \\
\hline \multicolumn{2}{|c|}{ SD } & 3.019 & & & & \\
\hline \multicolumn{2}{|l|}{$\% \mathrm{CV}$} & 3.94 & & & & \\
\hline
\end{tabular}

HQC: High-quality control, MQC: Middle-quality control, LQC: Low-quality control, SD: Standard deviation, CV: Coefficient of variation 
Sensitivity

The lowest limit of reliable quantification of canagliflozin in human plasma set at the concentration of the LLOQ is $10.13 \mathrm{ng} / \mathrm{ml}$. The precision and accuracy for canagliflozin at this concentration was found to be $2.83 \%$ and $95.65 \%$.

\section{Stability}

The stability of canagliflozin and internal standard was evaluated in plasma under different conditions such as freeze-thaw stability, bench-top stability, autosampler stability, and long-term stability. All the stabilities were carried out at two concentrations (28.893 $\mathrm{ng} / \mathrm{ml}$ and $5750.456 \mathrm{ng} / \mathrm{ml}$ ) as low and high concentration values with six determinations for each stability test along with calibration curve standards.

Table 4: ISTD normalized matrix factor

\begin{tabular}{lll}
\hline S. No. & HQC & LQC \\
\hline 1. & 1.05 & 1.05 \\
2. & 1.11 & 1.00 \\
3. & 1.12 & 1.04 \\
4. & 1.09 & 1.01 \\
5. & 1.05 & 0.97 \\
6. & 1.16 & 1.03 \\
7. & 1.11 & 1.01 \\
8. & 1.04 & 1.02 \\
Mean & 1.091 & 1.016 \\
SD & 0.0419 & 0.0250 \\
$\%$ CV & 3.84 & 2.46 \\
\hline
\end{tabular}

ISTD: Internal Standard, SD: Standard deviation, HQC: High-quality control, LQC: Low-quality control, CV: Coefficient of variation
The refrigerated stock solution stability of canagliflozin was carried out by injecting six replicates of internal standard. The precision ranged from $2.04 \%$ to $2.94 \%$ and percentage of stability was found to be $99.29 \%$. The internal standard precision ranged from $0.95 \%$ to $1.65 \%$ and percentage of stability was found to be $98.49 \%$.

The autosampler stability of canagliflozin was performed by injecting six sets of QC samples (LQC and HQC) and placed in autosampler for $67 \mathrm{~h} 15 \mathrm{~min}$. The percentage stability was $105.33 \%$ and $107.07 \%$ for HQC and LQC; percentage mean accuracy was $105.54 \%$ and $106.33 \%$, respectively. The results are shown in Table 5.

The analytes were found to be stable in dry as well as wet extract. The dry extract stability was carried out at room temperature, whereas wet extracted solubility was carried out at refrigerator temperature $\left(2-8^{\circ} \mathrm{C}\right)$. The wet extract stability for refrigerator temperature has been proved at $57 \mathrm{~h} 45 \mathrm{~min}$, ranged from $105.51 \%$ to $106.67 \%$ and precision ranged from $5.51 \%$ to $7.67 \%$, respectively. The values are shown in Table 6.

The dry extract solubility has been proven at room temperature for $10 \mathrm{~h}$ $15 \mathrm{~min}$, ranged from 100.41 to 104.925 and precision ranged from 1.98 to $7.27 \%$, respectively. The values are shown in Table 7 .

The freeze-thaw stability of canagliflozin was carried out for five cycles at $-28 \pm 5^{\circ} \mathrm{C}$. The percentage mean stability was $92.04-101.58 \%$ and precision was $3.48-4.57 \%$, respectively. The results are shown in Table 8.

The bench-top stability was carried out using six sets, each of LQC and $\mathrm{HQC}$ was determined at $17 \mathrm{~h} 5 \mathrm{~min}$. The percentage mean accuracy was

Table 5: Autosampler stability

\begin{tabular}{lllll}
\hline \multirow{2}{*}{. No. } & \multicolumn{3}{l}{ Back calculated concentration $\mathbf{( n g} / \mathbf{m l})$} & \\
\cline { 2 - 5 } & Comparison samples (FQC) & Stability samples & Comparison samples (FQC) & Stability samples \\
\hline 1. & 5525.235 & 5856.325 & 27.258 & 30.258 \\
2. & 5986.324 & 5936.235 & 28.698 & 31.254 \\
3. & 5635.231 & 6025.321 & 28.987 & 29.654 \\
4. & 6023.254 & 6125.364 & 29.654 & 31.257 \\
5. & 5864.365 & 6235.241 & 30.258 & 32.254 \\
6. & 5789.654 & 6234.214 & 26.365 & 29.654 \\
Mean & 5804.0105 & 6068.7833 & 28.5367 & 30.7218 \\
SD & 195.63077 & 156.76314 & 1.46899 & 1.04046 \\
\% CV & 3.37 & 2.58 & 5.15 & 3.39 \\
\% mean accuracy & 100.19 & 105.54 & 99.32 & 106.33 \\
\% mean stability & 105.33 & & 107.06 & \\
\% bias & 5.33 & 7.06 & \\
\hline
\end{tabular}

SD: Standard deviation, CV: Coefficient of variation, FQC: Final quality control

Table 6: Wet extract stability at refrigerator temperature

\begin{tabular}{lllll}
\hline \multirow{2}{*}{ S. No. } & \multicolumn{3}{l}{ Back calculated concentration $\mathbf{( n g} / \mathbf{m l})$} & \\
\cline { 2 - 5 } & Comparison samples & Stability samples & Comparison samples & Stability samples \\
\hline 1. & 5525.235 & 5865.234 & 27.258 & 30.254 \\
2. & 5986.324 & 5965.321 & 28.698 & 31.254 \\
3. & 5635.231 & 6025.321 & 28.987 & 29.365 \\
4. & 6023.254 & 6125.324 & 29.654 & 30.269 \\
5. & 5864.365 & 6235.214 & 30.258 & 32.254 \\
6. & 5789.654 & 6258.547 & 26.365 & 31.987 \\
Mean & 5804.0105 & 6079.1602 & 28.5367 & 30.8972 \\
SD & 195.63077 & 155.10380 & 1.46899 & 1.12344 \\
\% CV & 3.37 & 105.72 & 5.15 & 3.64 \\
\% mean accuracy & 100.19 & & 99.32 & 106.94 \\
\% mean stability & 105.51 & 107.67 & \\
\% bias & 5.51 & 7.67 & \\
\hline
\end{tabular}

\% mean accuracy: Percentage mean accuracy, \% CV: \% Coefficient of variation, SD: Standard deviation, FQC: Final quality control 
Table 7: Dry extract stability at room temperature

\begin{tabular}{|c|c|c|c|c|}
\hline \multirow[t]{2}{*}{ S. No. } & \multicolumn{4}{|c|}{ Back calculated concentration $(\mathrm{ng} / \mathrm{ml})$} \\
\hline & Comparison samples & Stability samples & Comparison samples & Stability samples \\
\hline 1. & 5525.235 & 6023.542 & 27.258 & 25.365 \\
\hline 3. & 5635.231 & 6025.321 & 28.987 & 29.657 \\
\hline 4. & 6023.254 & 5898.365 & 29.654 & 31.254 \\
\hline 5. & 5864.365 & 6123.254 & 30.258 & 27.687 \\
\hline 6. & 5789.654 & 6235.247 & 26.365 & 30.257 \\
\hline Mean & 5804.0105 & 6044.8305 & 28.5367 & 28.8128 \\
\hline SD & 195.63077 & 119.45658 & 1.46899 & 2.09461 \\
\hline$\% \mathrm{CV}$ & 3.37 & 1.98 & 5.15 & 7.27 \\
\hline$\%$ mean accuracy & 100.19 & 105.12 & 99.32 & 99.72 \\
\hline$\%$ mean stability & 104.92 & & 100.41 & \\
\hline$\%$ bias & 4.92 & & 0.41 & \\
\hline
\end{tabular}

SD: Standard deviation, CV: Coefficient of variation, SD: Standard deviation, FQC: Final quality control

Table 8: Freeze-thaw stability

\begin{tabular}{llll}
\hline S. No. & \multicolumn{2}{l}{ Back calculated concentration $(\mathbf{n g} / \mathbf{m l})$} & \\
\cline { 2 - 3 } & \multicolumn{1}{l}{ Comparison samples } & Stability samples & Comparison samples \\
\hline 1. & 5525.235 & 5026.354 & 27.258 \\
2. & 5986.324 & 5124.258 & 28.698 \\
3. & 5635.231 & 5264.258 & 28.987 \\
4. & 6023.254 & 5525.365 & 29.654 \\
5. & 5864.365 & 5654.258 & 30.258 \\
6. & 5789.654 & 5458.254 & 26.365 \\
Mean & 5804.0105 & 5342.1245 & 28.5367 \\
SD & 195.63077 & 244.02069 & 1.46899 \\
\% CV & 3.37 & 4.57 & 5.15 \\
\% mean accuracy & 100.93 & 92.90 & 98.77 \\
\% mean stability & 92.04 & & 101.58 \\
\% bias & -7.96 & & 29.354 \\
\hline
\end{tabular}

\% mean stability: Percentage mean stability, \% mean accuracy: Percentage mean accuracy. SD: Standard deviation, CV: Coefficient of variation, FQC: Final quality control

Table 9: Long-term stability

\begin{tabular}{llll}
\hline S. No. & \multicolumn{2}{l}{ Back calculated concentration (ng/ml) } & \\
\cline { 2 - 4 } & Comparison samples (FQC) & Stability samples & Comparison samples (FQC) \\
\hline 1. & 5636.354 & 6235.354 & 28.365 \\
2. & 5863.254 & 6125.324 & 29.365 \\
3. & 5963.214 & 6023.254 & 30.254 \\
4. & 6123.547 & 5965.321 & 31.254 \\
5. & 6025.321 & 6032.214 & 29.365 \\
6. & 6124.254 & 6125.234 & 31.254 \\
Mean & 5955.9907 & 6084.4502 & 29.9762 \\
SD & 185.48004 & 96.71743 & 1.15636 \\
\% CV & 3.11 & 1.59 & 3.86 \\
\% mean accuracy & 103.04 & 105.81 & 104.25 \\
\% bias & 102.69 & & 101.16 \\
\hline
\end{tabular}

SD: Standard deviation, CV: Coefficient of variation, FQC: Final quality control

108.82-109.21\%, respectively, and the precision range was from 2.04 to $2.47 \%$, respectively.

The long-term matrix stability of QC samples was stored at $-28 \pm 5^{\circ} \mathrm{C}$ for 91 days which was assessed. The percentage stability was found to be 101.16-102.69\%; coefficient of variation was $1.59-3.69$. These values indicate that the canagliflozin is stable for at least 91 days; it should be analyzed within this period. The results are shown in Table 9.

\section{CONCLUSION}

The results of matrix effect, linearity, precision, accuracy, stabilities, and recovery were in the acceptable range as per guidance for industrybioanalytical method validation. The LC-MS/MS method described above is valid for the estimation of canagliflozin in human plasma over a range of 462.500/267.100 with the detection of canagliflozin (m/z) and internal standard canagliflozin $\mathrm{D}_{4} 466.400 / 267.200(\mathrm{~m} / \mathrm{z})$ in positive ion mode.

\section{ACKNOWLEDGMENT}

The author would like to thank Mr. Anupindi raghuram,Krish biotech for providing sample to carryout the research work.

\section{AUTHORS' CONTRIBUTIONS}

All authors contributed equally to the paper. 


\section{CONFLICTS OF INTEREST}

The author declares that they have no conflicts of interest.

\section{REFERENCES}

1. Available from: https://www.drugbank.ca/drugs/DB08907.

2. Kaushal S, Singh H, Thangaraju P, Singh J. Canagliflozin: A Novel SGLT2 inhibitor for Type 2 diabetes mellitus. N Am J Med Sci 2014;6:107-13.

3. Kaur I, Wakode S, Singh HP. Development and validation of stability indicating UV spectroscopic method for determination of canagliflozin in bulk and pharmaceutical dosage form. Pharm Methods 2016;7:63-9.

4. Iqbal M, Khalil NY, Alanazi AM, Al-Rashooda KA. A simple and sensitive high-performance liquid chromatography assay with a fluorescence detector for determination of canagliflozin in human plasma. Anal Methods 2015;7:3028-35.

5. Sen G, Babu KR, Annapurna N, Vekariya NA. Validation of stabilityindicating reverse phase HPLC method for the determination of related substances in canagliflozin drug substance. IOSR J Pharm Biol Sci 2017;12:86-94.

6. Suneetha A, Sharmila D. A validated stability indicating RP-HPLC method for estimation of canagliflozin in dosage form. Res J Pharm Biol Chem Sci 2015;6:1186-94.

7. Ashok P, Narenderan ST, Meyyanathan SN, Babu B, Vadivelan R. Development and validation of a RP-HPLC method for estimation of telmisartan in human plasma. Int J Appl Pharm Res 2019;11:237-40.

8. Kaur I, Wakode S, Singh HP. Development and validation of a stabilityindicating high-performance thin layer chromatography (HPTLC) method for estimation of canagliflozin in bulk and pharmaceutical dosage form. J Appl Pharm Sci 2016;6:51-7.

9. Kobuchi S, Yano K, Ito Y, Sakaeda T. A validated LC-MS/MS method for the determination of canagliflozin, a sodium-glucose co-transporter 2 (SGLT-2) inhibitor, in a lower volume of rat plasma: Application to pharmacokinetic studies in rats. Biomed Chromatogr 2016;30:1549-55.

10. Prasad PB, Satyanarayana K, Mohan GK. Simultaneous determination of metformin, linagliptin in jentadueto and metformin, saxagliptin in kombiglyze by LC-MS method. Int J Pharm Pharm Sci 2018;10:110-6.

11. Pinjari MJ, Somani RS, Gilhotra RM. A rapid, sensitive and validated ultra-performance liquid chromatography and tandem mass spectrometry method for determination of paromomycin in Mice plasma: Application to pharmacokinetic study. Int J Pharm Pharm Sci 2017;9:86-90

12. Guidance for Industry Bioanalytical Method Validation; 2013 